\title{
Two microsatellite repeat polymorphisms flanking opposite ends of the human glucokinase gene: use in haplotype analysis of Welsh Caucasians with Type 2 (non-insulin-dependent) diabetes mellitus
}

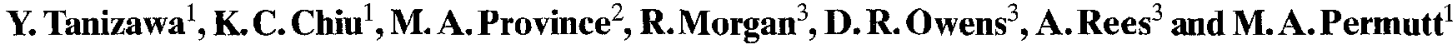 \\ ${ }^{1}$ Department of Internal Medicine, Division of Endocrinology, Diabetes, and Metabolism; Washington University School of Medicine, \\ St. Louis, Missouri, USA \\ ${ }^{2}$ Division of Biostatistics, Washington University School of Medicine, St. Louis, Missouri, USA \\ ${ }^{3}$ University Hospital of Wales, Cardiff, Wales, UK
}

\begin{abstract}
Summary. The purpose of this study was to evaluate the role of potential glucokinase defects contributing to susceptibility to Type 2 (non-insulin-dependent) diabetes mellitus in Welsh Caucasians. For this analysis, two microsatellite repeat polymorphisms flanking opposite ends of the gene were employed. For a recently described microsatellite (GCK2), located 6 kilobases upstream of islet exon 1, six different sized alleles were observed, with heterozygosity of 0.50 and polymorphism information content 0.44 . Combined heterozygosity with another microsatellite repeat (GCK1) was 0.72. Significant linkage disequilibrium was noted between GCK2 and GCK1, suggesting that haplotypes may be a better predictor of Type 2 diabetes than analysis with either microsatellite alone. Using these two markers, the association with Type 2 diabetes was examined. The frequencies of alleles and genotypes at GCK1 did not differ between the patients with Type 2 diabetes $(n=157)$ and control subjects $(n=73)$. Simi-
\end{abstract}

larly no differences were observed in GCK2 alleles or genotypes. The frequencies of haplotypes, derived from the two markers, also did not differ between the two groups. To investigate the possibility of minor metabolic effects of glucokinase defects, we also studied the association between the GCK alleles or haplotypes and the response profiles to meal tolerance tests. No association was observed between plasma glucose or insulin responses to meal tolerance tests with GCK haplotypes or alleles. These results suggest that glucokinase mutations in Welsh Caucasians are not major determinants of susceptibility to the common type of Type 2 diabetes.

Key words: Glucokinase gene, microsatellite, polymorphism, linkage disequilibrium, haplotypes, Type 2 (non-insulindependent) diabetes mellitus.
Glucokinase (ATP:D-hexose 6-phosphotransferase, EC 2.7.1.1) [1], the major glucose phosphorylating enzyme in pancreatic islet beta cells and liver [2], has been considered to be a major component of glucose sensing in islet beta cells, and thus a candidate for a determinant of genetic susceptibility to diabetes mellitus [3]. Isolation of rat glucokinase cDNAs $[4,5]$ and the gene $[5,6]$ made it possible to study this gene in humans. First human cDNAs were isolated from liver [7] and islet [8] cDNA libraries. Then partial genomic clones were isolated, a polymorphic microsatellite (GCK1) was identified and the gene was mapped to chromosome $7 \mathrm{p}$ [9]. Very recently, the complete structure of the gene was determined, and a new polymorphic microsatellite (GCK2) was identified [10]. This microsatellite, and the gene structure, were independently confirmed [11, 12].

The microsatellites at the glucokinase locus provided the means with which to assess the role of potential glucokinase defects in diabetes. Using these polymorphicmarkers, tight linkage of the glucokinase locus with several French
[13] and English [14] MODY pedigrees, a special type of early-onset Type 2 (non-insulin-dependent) diabetes, was shown. In these pedigrees mutations were identified in the structural region of the gene resulting in a defective glucokinase enzyme [12, 15-17]. In this subset of MODY with glucokinase defects, a distinct phenotype is being clarified $[14,18]$, i. e. early onset in affected family members of mild glucose intolerance, with moderately elevated fasting blood glucose and normal insulin levels. An important question remaining to be answered is the role of glucokinase defectsin patients with common (or late onset) Type 2 diabetes. In contrast to MODY, for common Type 2 diabetes, the mode of inheritance is unclear and even within a single family, multiple factors, both genetic and environmental, are likely to contribute. Thus segregation of any one gene may be difficult to discern $[19,20]$.

Alternative ways of evaluating a candidate locus are population association studies, based on the assumption that a mutation at the locus is in linkage disequilibrium with a specific polymorphic allele, within or near the locus 
Table 1. GCK2 allelic frequency

\begin{tabular}{crcrr}
\hline Allele $^{\mathrm{a}}$ & \multicolumn{2}{c}{ Type 2 diabetes } & \multicolumn{2}{c}{ Control subjects } \\
\hline-12 & 5 & $1.6 \%$ & 3 & $2.1 \%$ \\
-4 & 5 & $1.6 \%$ & 1 & $0.7 \%$ \\
-2 & 18 & $5.7 \%$ & 2 & $1.4 \%$ \\
0 & 207 & $65.9 \%$ & 95 & $65.1 \%$ \\
2 & 79 & $25.2 \%$ & 44 & $30.1 \%$ \\
6 & 0 & - & 1 & $0.7 \%$ \\
Total & 314 & & 146 & \\
\hline
\end{tabular}

GCK2 genotypic frequency

\begin{tabular}{lrrrr}
\hline Genotype $^{\mathrm{b}}$ & \multicolumn{2}{c}{ Type 2 diabetes } & \multicolumn{2}{c}{ Control subjects } \\
\hline$-2 /-2^{\mathrm{c}}$ & 2 & $1.3 \%$ & 0 & $0.0 \%$ \\
$0 /-12^{\mathrm{c}}$ & 5 & $3.2 \%$ & 2 & $2.7 \%$ \\
$0 /-4^{\mathrm{c}}$ & 2 & $1.3 \%$ & 1 & $1.4 \%$ \\
$0 /-2$ & 9 & $5.7 \%$ & 0 & $0.0 \%$ \\
$0 / 0$ & 70 & $44.6 \%$ & 32 & $43.8 \%$ \\
$2 /-12^{\mathrm{c}}$ & 0 & $0.0 \%$ & 1 & $1.4 \%$ \\
$2 /-4^{\mathrm{c}}$ & 3 & $1.9 \%$ & 0 & $0.0 \%$ \\
$2 /-2^{\mathrm{c}}$ & 5 & $3.2 \%$ & 2 & $2.7 \%$ \\
$2 / 0$ & 51 & $32.5 \%$ & 27 & $37.0 \%$ \\
$2 / 2$ & 10 & $6.4 \%$ & 7 & $9.6 \%$ \\
$6 / 0^{\mathrm{c}}$ & 0 & - & 1 & $1.4 \%$ \\
Total & 157 & & 73 & \\
\hline
\end{tabular}

${ }^{\mathrm{a}} p=0.146\left(\chi^{2}=8.200, d f=5\right),{ }^{\mathrm{b}} p=0.262\left(\chi^{2}=5.261, d f=4\right)$ control subjects vs Type 2 diabetic patients. ${ }^{c}$ Values are pooled for calculation

[21]. Most important, association studies provide a means to detect minor predisposing factors, which may be difficult to recognize by linkage analysis. In this respect, association studies may define 'gene effects, even in a genetically heterogeneous disorder [21].

The purpose of the present study was to utilize the two microsatellite repeat polymorphisms to assess the role of the glucokinase gene in the susceptibility to late-onset Type 2 diabetes in a population of unrelated Welsh Caucasians. In this context, in American Blacks [22], Mauritian Creoles [23] and Japanese (Noda K, Matsutani A, Tanizawa Y, Permutt MA, Kaneko T, Kaku K, unpublished data) certain alleles in GCK1 were shown to be associated with late-onset Type 2 diabetes. Here we characterized a recently described microsatellite (GCK2) polymorphism, and defined its relationship to GCK1. Using both markers, haplotypes were defined. As significant linkage disequilibrium was noted over at least 50 kilobases of DNA, the potential role of regulatory defects, as well as coding gene defects, could be assessed by these studies. The results indicate that a common glucokinase mutation is not present in Caucasian Type 2 diabetic patients.

\section{Subjects and methods}

\section{Study population and DNA preparation}

Well-characterized, unrelated Welsh Caucasian patients with Type 2 diabetes $(n=157$, mean age $53.2 \pm 10.5$ years, body mass index $\left.28.8 \pm 5.3 \mathrm{~kg} / \mathrm{m}^{2}\right)$ and control subjects $(n=73$, mean age $65.9 \pm 10.2$ years, body mass index $\left.24.6 \pm 4.8 \mathrm{~kg} / \mathrm{m}^{2}\right)[24,25]$ were studied. A meal tolerance test (MTT) of $500 \mathrm{kcal}(60 \%$ carbohy- drate), plasma glucose and insulin determination and DNA extraction were carried out as described [24].

\section{Polymerase chain reaction amplification and sequencing of the microsatellites}

Polymerase chain reaction (PCR) amplification of GCK1 and GCK2 was done as described $[9,10]$. For amplification of GCK2, a new set of primers \#15796 (5'-gggacattgtgtctgcaacttactc-3') and $\# 15795$ ( $5^{\prime}$-cagatacgcttcatcctgattcetg- $\left.3^{\prime}\right)$ was also used under the same PCR condition except that an annealing temperature of $69^{\circ} \mathrm{C}$ was used. The product from this set of primers was 146 base pairs (bp) for the " 0 " allele. Sequences of GCK2 alleles were determined by direct sequencing of the PCR products as described [10]. Haplotypes of the GCK1 and GCK2 were determined for the individuals who were homozygous for at least one of the two loci. Polymorphism information content (PIC) and heterozygosity of each allele $\left(\mathrm{HET}_{\mathrm{GCK} 1}, \mathrm{HET}_{\mathrm{GCK} 2}\right)$ was calculated as described [9]. Combined heterozygosity was calculated by the formula: $\left(\mathrm{HET}_{\mathrm{GCK} 1}+\right.$ $\left.\mathrm{HET}_{\mathrm{GCK} 2}\right)-\left(\mathrm{HET}_{\mathrm{GCK} 1} \times \mathrm{HET}_{\mathrm{GCK} 2}\right)$.

\section{Statistical analysis}

The frequency distribution of GCK alleles, genotypes and haplotypes were compared between Type 2 diabetic patients and control subjects by chi-square tests. To assess the possible impact of each allele at each locus and of the entire haplotype, a series of multivariate categorical models were fit, using a logistic response function [26] as implemented in SAS/CATMOD (SAS Institute, 1989). A stepwise approach was also used in this context, to find the most parsimonious set of alleles or haplotypes which distinguished Type 2 diabetes from the control subjects [22]. Linkage disequilibrium between the two microsatellite loci was tested by a Fisher's exact test (two-tailed) comparing observed vs expected haplotype frequencies for the Type 2 diabetes and the control groups combined. The expected haplotype frequencies were calculated from the allelic frequency of each loci in this haplotyped subpopulation (data not shown) assuming these two loci were randomly associated. Glucose and insulin responses to MTT were compared by an unpaired $t$-test between the groups with or without specific alleles or haplotypes.

\section{Results}

\section{Characterization of $G C K 2$ and linkage disequilibrium with $G C K 1$}

Polymerase chain reaction (PCR) amplification with oligonucleotide primers flanking the $5^{\prime}$-microsatellite repeat GCK2 resulted in six different sized alleles in Welsh Caucasians (Table 1). The sizes of the alleles could be accurately determined by electrophoresis on polyacrylamide sequencing gels. The sequences of each allele were confirmed directly from genomic DNA on selected individuals. The " 0 " allele, $146 \mathrm{bp}$ in length amplified with primers 15795 and 15796, was defined as the most common allele, and the other alleles differed from the " 0 " allele in general by the number of GT or GA repeats [10]. Thus the "2" allele has 2 bp more, and the " -2 " allele has 2 bp less than the " 0 " allele, respectively. Frequencies of the GCK2 alleles and genotypes are shown (Table 1). Heterozygosity (HET) for GCK2 was 0.50 and polymorphism information content (PIC) 0.44 for the group as a whole. At the 
Table 2. GCK1 allelic frequency

\begin{tabular}{lrrrr}
\hline Allele $^{\mathrm{a}}$ & \multicolumn{2}{c}{ Type 2 diabetes } & \multicolumn{2}{c}{ Control subjects } \\
\hline $\mathrm{Z}$ & 216 & $68.8 \%$ & 114 & $78.1 \%$ \\
$\mathrm{Z}+2$ & 18 & $5.7 \%$ & 4 & $2.7 \%$ \\
$\mathrm{Z}+4$ & 77 & $24.5 \%$ & 27 & $18.5 \%$ \\
$\mathrm{Z}+6$ & 0 & - & 1 & $0.7 \%$ \\
$\mathrm{Z}+8$ & 1 & $0.3 \%$ & 0 & - \\
$\mathrm{Z}+10$ & 2 & $0.6 \%$ & 0 & - \\
Total & 314 & & 146 & \\
\hline
\end{tabular}

GCK1 genotypic frequency

\begin{tabular}{lrrrr}
\hline Genotype $^{\mathrm{b}}$ & \multicolumn{2}{c}{ Type 2 diabetes } & \multicolumn{2}{c}{ Control subjects } \\
\hline $\mathrm{Z} / \mathrm{Z}$ & 73 & $46.5 \%$ & 45 & $61.4 \%$ \\
$\mathrm{Z} / \mathrm{Z}+2$ & 16 & $10.2 \%$ & 2 & $2.7 \%$ \\
$\mathrm{Z} / \mathrm{Z}+4$ & 51 & $32.5 \%$ & 21 & $28.8 \%$ \\
$\mathrm{Z} / \mathrm{Z}+6^{\mathrm{c}}$ & 0 & - & 1 & $1.4 \%$ \\
$\mathrm{Z} / \mathrm{Z}+8^{\mathrm{c}}$ & 1 & $0.6 \%$ & 0 & - \\
$\mathrm{Z} / \mathrm{Z}+10^{\mathrm{c}}$ & 2 & $1.3 \%$ & 0 & - \\
$\mathrm{Z}+2 / \mathrm{Z}+4^{\mathrm{c}}$ & 2 & $1.3 \%$ & 2 & $2.7 \%$ \\
$\mathrm{Z}+4 / \mathrm{Z}+4$ & 12 & $7.6 \%$ & 2 & $2.7 \%$ \\
Total & 157 & & 73 & \\
\hline
\end{tabular}

${ }^{\mathrm{a}} p=0.145\left(\chi^{2}=8.214, d f=5\right)$,

b $p=0.089\left(\chi^{2}=8.074, d f=4\right)$ control subjects vs Type 2 diabetic patients.

${ }^{c}$ Values are pooled for calculation

GCK1 locus, HET was 0.43 and PIC 0.38 in the same population (Table 2). Combined heterozygosity for GCK1 and GCK2 was estimated to be 0.72 , indicating that use of both microsatellites would increase informativeness for family analysis.

Haplotypes could be resolved for individuals who were homozygous at one or more of these two loci (179 of 230 total individuals studied, Table 3 ). The genotype combinations and the frequencies of those who could not be haplotyped are also shown (Table 3). These haplotypes were used to determine whether linkage disequilibrium existed between GCK1 and GCK2. Haplotype frequencies did not differ between patients with Type 2 diabetes and control subjects (see below), so the data from the two groups were pooled for this analysis. Comparing observed haplotype frequencies with those expected if the two loci were randomly associated, significant linkage disequilibrium was noted between the two loci ( $p=0.001$, Fisher's exact test, data not shown).

Allele, genotype, and haplotype frequencies for GCK1 and $G C K 2$ in patients with Type 2 diabetes and control subjects

Allele and genotype frequencies at GCK2 and GCK1 loci in patients with Type 2 diabetes $(n=157)$ and control subjects $(n=73)$ were determined. Genotype frequencies for both diabetic patients and control subjects did not differ from those predicted from Hardy-Weinberg equilibrium (data not shown). The distribution of the GCK2 genotypes and allele frequencies was not different between the control group and the diabetic group (Table 1). Similarly for the GCK1 locus, the distribution of allele and geno- type frequencies did not differ between diabetic and control groups (Table 2). Next, we looked to see if each allele in turn had a significantly greater predictive effect (either positive or negative) on the risk of Type 2 diabetes than all others. None of the GCK1 and GCK2 alleles were found to be associated with Type 2 diabetes (data not shown). Haplotypes were determined for 120 diabetic $(76.4 \%)$ and 59 non-diabetic individuals $(80.8 \%)$. The frequency distribution of haplotypes also did not differ between the two groups (Table 3), and no haplotype appeared to be associated with Type 2 diabetes (data not shown).

\section{Metabolic profiles and GCK haplotypes in patients with Type 2 diabetes}

To investigate whether specific GCK1, GCK2 alleles, or haplotypes could influence the metabolic profiles, we compared the glucose and insulin responses to MTT between the Type 2 diabetic patients with or without each allele or haplotype. The results of the comparisons between the groups with or without each of three major GCK haplotypes are shown in Table 4. Age and body mass index were not different between each set of the groups. Glucose and insulin values were compared at time 0,30 and $120 \mathrm{~min}$ after the MTT to evaluate basal state, early and peak responses. No differences were observed in either glucose or insulin responses at any of the time points. The results were similar when the responses were compared between the patients who were homozygous for the par-

Table 3. Haplotype frequency

\begin{tabular}{lrrrr}
\hline $\begin{array}{l}\text { Haplotype } \\
\text { (GCK1/GCK2) }\end{array}$ & \multicolumn{2}{l}{ Type 2 diabetes } & \multicolumn{2}{l}{ Control subjects } \\
\hline $\mathrm{Z} /-12^{\mathrm{b}}$ & 2 & $0.8 \%$ & 2 & $1.7 \%$ \\
$\mathrm{Z} /-4^{\mathrm{b}}$ & 2 & $0.8 \%$ & 1 & $0.8 \%$ \\
$\mathrm{Z} / 2^{\mathrm{b}}$ & 3 & $1.3 \%$ & 0 & $0.0 \%$ \\
$\mathrm{Z} / 0$ & 125 & $52.1 \%$ & 68 & $57.6 \%$ \\
$\mathrm{Z} / 2$ & 49 & $20.4 \%$ & 31 & $26.3 \%$ \\
$\mathrm{Z}+2 / 0^{\mathrm{b}}$ & 7 & $2.9 \%$ & 1 & $0.8 \%$ \\
$\mathrm{Z}+2 / 2^{\mathrm{b}}$ & 1 & $0.4 \%$ & 0 & $0.0 \%$ \\
$\mathrm{Z}+4 /-4^{\mathrm{b}}$ & 1 & $0.4 \%$ & 0 & $0.0 \%$ \\
$\mathrm{Z}+4 /-2^{\mathrm{b}}$ & 5 & $2.1 \%$ & 0 & $0.0 \%$ \\
$\mathrm{Z}+4 / 0$ & 41 & $17.1 \%$ & 13 & $11.0 \%$ \\
$\mathrm{Z}+4 / 2^{\mathrm{b}}$ & 2 & $0.8 \%$ & 1 & $0.8 \%$ \\
$\mathrm{Z}+6 / 0^{\mathrm{b}}$ & 0 & $0.0 \%$ & 1 & $0.8 \%$ \\
$\mathrm{Z}+10 / 0^{\mathrm{b}}$ & 2 & $0.8 \%$ & 0 & $0.0 \%$ \\
Total & 240 & & 118 & \\
\hline
\end{tabular}

Frequency of genotype combination (non-haplotyped individuals)

\begin{tabular}{lrrrr}
\hline $\begin{array}{l}\text { Genotype }^{c} \\
\text { (GCK1, GCK2) }\end{array}$ & \multicolumn{2}{c}{ Type 2 diabetes } & \multicolumn{2}{c}{ Control subjects } \\
\hline $\mathrm{Z} / \mathrm{Z}+2, \quad 0 / 2$ & 5 & $13.5 \%$ & 1 & $7.1 \%$ \\
$\mathrm{Z} / \mathrm{Z}+4, \quad 0 / 2$ & 15 & $40.5 \%$ & 8 & $57.1 \%$ \\
$\mathrm{Z} / \mathrm{Z}+4, \quad 0 /-2$ & 6 & $16.2 \%$ & 0 & $0.0 \%$ \\
$\mathrm{Z} / \mathrm{Z}+4, \quad 2 /-2$ & 3 & $8.1 \%$ & 2 & $14.3 \%$ \\
Others & 8 & $21.7 \%$ & 3 & $21.5 \%$ \\
Total & 37 & & 14 & \\
\hline
\end{tabular}

${ }^{\mathrm{a}} p=0.103,\left(\chi^{2}=6.191, d f=3\right) .{ }^{\mathrm{b}}$ Values are pooled for calculation ${ }^{c} p=0.457\left(\chi^{2}=3.61, d f=4\right)$, Genotype combinations less than $6 \%$ in frequency ( $n<3$ in Type 2 diabetes) were pooled 
Table 4. Age, body mass index (BMI), and meal tolerance test blood glucose and insulin responses by glucokinase haplotypes

\begin{tabular}{|c|c|c|c|c|c|c|c|c|c|}
\hline \multirow[b]{2}{*}{ Haplotype } & \multirow[b]{2}{*}{$n$} & \multirow[b]{2}{*}{ Age (years) } & \multirow[b]{2}{*}{$\mathrm{BMI}\left(\mathrm{kg} / \mathrm{m}^{2}\right)$} & \multicolumn{3}{|c|}{ Glucose $(\mathrm{mmol} / \mathrm{l})$} & \multicolumn{3}{|c|}{ Insulin (pmol/l) } \\
\hline & & & & $0 \mathrm{~min}$ & $30 \mathrm{~min}$ & $120 \mathrm{~min}$ & $0 \min$ & $30 \mathrm{~min}$ & $120 \mathrm{~min}$ \\
\hline $\mathrm{Z} / 0$ & 82 & $53.9 \pm 10.2$ & $29.0 \pm 5.3$ & $11.4 \pm 3.2$ & $13.4 \pm 3.5$ & $15.2 \pm 4.7$ & $94.5 \pm 68.9$ & $182.1 \pm 113.0$ & $378.4 \pm 315.6$ \\
\hline non $\mathbf{Z} / 0$ & 22 & $51.6 \pm 9.0$ & $28.2 \pm 5.7$ & $12.8 \pm 3.5$ & $14.9 \pm 3.6$ & $16.4 \pm 4.8$ & $89.8 \pm 58.5$ & $196.9 \pm 185.0$ & $287.6 \pm 325.9$ \\
\hline $\mathrm{Z} / 2$ & 33 & $52.6 \pm 9.2$ & $29.6 \pm 6.4$ & $11.4 \pm 3.0$ & $13.5 \pm 3.2$ & $15.0 \pm 4.0$ & $102.5 \pm 69.9$ & $194.9 \pm 122.5$ & $403.7 \pm 417.7$ \\
\hline non $\mathrm{Z} / 2$ & 71 & $53.7 \pm 10.3$ & $28.5 \pm 4.8$ & $11.8 \pm 3.5$ & $13.8 \pm 3.7$ & $15.7 \pm 5.1$ & $89.3 \pm 65.0$ & $180.7 \pm 134.8$ & $338.4 \pm 260.8$ \\
\hline $\mathrm{Z}+4 / 0$ & 32 & $52.1 \pm 10.0$ & $29.0 \pm 5.2$ & $12.1 \pm 3.4$ & $14.0 \pm 3.5$ & $15.7 \pm 4.1$ & $103 \pm 73.5$ & $193.1 \pm 158.4$ & $366.5 \pm 330.3$ \\
\hline
\end{tabular}

Values are mean \pm SD

$5^{\prime}$

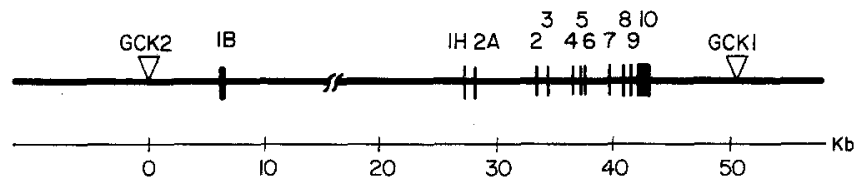

Fig. 1. Structure of the human glucokinase gene, adapted from ref [10]. The position of each exon is shown by vertical bars: $1 \mathrm{~B}$ refers to islet exon $1,1 \mathrm{H}$ to liver exon 1 , and $2 \mathrm{~A}$ to the cassette exon expressed in the variant liver glucokinase. The positions of polymorphic microsatellite repeats, GCK 2 in the $5^{\prime}$ and GCK 1 in the $3^{\prime}$ flanking region of the gene, are indicated by downward arrowheads

ticular haplotype and those who did not have the haplotype (data not shown). No independent GCK1 or GCK2 alleles were identified which influenced the profile of the responses to MTT (data not shown).

\section{Discussion}

In this report a recently described $[10,13]$ polymorphic microsatellite (GCK2), which was mapped to a location 6 $\mathrm{kb}$ upstream $\left(5^{\prime}\right)$ of the islet glucokinase promoter (Fig. 1), was characterized. Nishi et al. [11] recently described a microsatellite repeat in the $5^{\prime}$-region of islet exon 1 of glucokinase gene, which was identical to GCK2. The relationship of GCK2 to the previously described microsatellite GCK1, which flanked the glucokinase gene on the $3^{\prime}$ end [9], was also defined. Heterozygosity was as great at GCK2 (0.50) as at GCK1 (0.43). Combined with GCK1, the heterozygosity increased to 0.72 . The two microsatellites together make the glucokinase locus a highly informative one for linkage analysis in families. Linkage disequilibrium between the two microsatellites was also evaluated. Significant linkage disequilibrium was observed, suggesting that if mutations exist in this greater than $50 \mathrm{~kb}$ region around the glucokinase gene, the mutations might be in linkage disequilibrium with specific glucokinase alleles.

The association of the two glucokinase microsatellites with late-onset Type 2 diabetes was studied in a well-characterized population of Welsh Caucasians. Neither GCK1 or GCK2 alleles, nor haplotypes defined by both loci, appeared to be associated with Type 2 diabetes. To investigate the possibility of minor metabolic effects of glucokinase defects, we studied the association between the GCK alleles or haplotypes and the response profiles to MTT. We could not observe specific characteristics of plasma glucose or insulin responses to MTT in Type 2 diabetic pa- tients associated with GCK haplotypes or alleles. These results suggested that in this Caucasian population, common mutations in the glucokinase gene are not a major determinant of diabetic susceptibility.

Population association studies are not without problems. Comparability of cases and controls are important, as frequencies of genetic markers can vary considerably among ethnic and racial groups. In this study, patients and control subjects were recruited from the same Welsh Caucasian community. As a result of the fact that the patients and control subjects were selected only by the criteria of diabetes status, mean age and BMI were significantly different between these two groups. We cannot exclude the impact of these differences on the analysis. Also, if susceptibility alleles arise on the most common haplotypes, there may be little power to detect an association [21]. Furthermore, the same mutation must be frequent in affected individuals. If many different mutations exist at the candidate locus, no one allele will be found to be associated with the disease. A solution to this potential problem is molecular scanning at the single nucleotide level, by methods such as single strand conformational polymorphism (SSCP) [27], and linkage analysis in families. Nevertheless, in the SSCP analysis, it is often difficult to screen the entire gene, and mutations in regulatory regions could easily be missed because for most genes the regulatory regions are not well characterized. In retrospect, linkage studies in MODY were successful because these distinct phenotypes represent a subtype of the more heterogeneous Type 2 diabetes, identified with relatively easily quantifiable parameters. However, other mutations, even in the glucokinase gene if within the regulatory regions for example, could result in more subtle phenotypes which could be more difficult to quantitate. In such a case, even within a single family, multiple factors, both genetic and environmental, are likely to be contributing to Type 2 diabetes, and thus segregation of any one gene may be difficult to discern $[19,20]$. This problem has already been encountered even in a MODY family with linkage to the ADA locus on chromosome $20 \mathrm{q}$ [28].

Population association studies may supplement the shortcomings of molecular scanning and linkage analysis. Association studies allow evaluation of a genetic locus over a region of up to $100 \mathrm{~kb}$ of DNA [29], which covers the whole gene including the regulatory regions, and can be performed without large multigenerational families. Most important, association studies provide a means of detecting minor predisposing factors (i.e. mutations whose effects are minor by themselves and hard to be 
identified as a certain phenotype), which may be difficult to be recognized by linkage analysis. Therefore all of these approaches are complementary and essential to study the genetics of a complex disorder such as Type 2 diabetes.

Linkage analysis in families $[30,31]$ as well as preliminary results of SSCP analysis in Caucasian late-onset Type 2 diabetic patients showed similar lack of positive findings. Thus, the results of the current analysis, along with the other studies, strongly suggest that for common Type 2 diabetes in Caucasians, common glucokinase mutations will not be a predominant factor in genetic susceptibility to this disease. Whether the previous associations observed in American Blacks [22], Mauritian Creoles [23], and Japanese (Noda K, Matsutani A, Tanizawa Y, Permutt MA, Kaneko T, Kaku K, unpublished data) represent differencesin the genetic basis of the common Type 2 diabetes between racial groups has yet to be determined.

Acknowledgements. This work was supported in part by grants DK16746 (MA Permutt), GM28719 (MA Province), and DK07120 ( $\mathrm{KC} \mathrm{Chiu)} \mathrm{from} \mathrm{the} \mathrm{National} \mathrm{Institute} \mathrm{of} \mathrm{Health,} \mathrm{and} \mathrm{RR00036} \mathrm{and}$ the Diabetic Research and Training Center at Washington University (DK20575) from the U.S.Public Health Service. Y.Tanizawa was the recipient of a Mentor-based Fellowship Award from the American Diabetes Association. The laboratory assistance of Ms R. Janssen and Ms C. Welling and manuscript preparation by $\mathrm{Ms}$ J. Wokurka are also gratefully acknowledged.

\section{References}

1. Iynejian P, Girard J (1991) Nomenclature for mammalian glucokinase. Biochem J 275: 821-823

2. Colowick SP (1973) The hexokinases. In: Boyer PD (ed) The enzymes, vol 9. Academic Press, New York, pp 1-48

3. Matschinsky FM (1990) Glucokinase as glucose sensor and metabolic signal generator in pancreatic $\beta$-cells and hepatocytes. Diabetes 39: 647-652

4. Andreone TL, Printz RL, Pilkis SJ, Magnuson MA, Granner DK (1980) The amino acid sequence of rat liver glucokinase deduced from cloned cDNA. J Biol Chem 264: 363-369

5. Magnuson MA, Shelton KD (1989) An alternate promoter in the glucokinase gene is active in the pancreatic $\beta$ cell. $\mathrm{J}$ Biol Chem 264: 15936-15942

6. Magnuson MA, Andreone TL, Printz RL, Koch S, Granner DK (1989) Rat glucokinase gene: structure and regulation by insulin. Proc Natl Acad Sci USA 86: 4838-4842

7. Tanizawa Y, Koranyi LI, Welling CM, Permutt MA (1991) Human liver glucokinase gene: cloning and sequence determination of two alternatively spliced cDNAs. Proc Natl Acad Sci USA 88: 7294-7297

8. Koranyi LI, Tanizawa Y, Welling CM, Rabin DU, Permutt MA (1982) Human islet glucokinase gene: isolation and sequence analysis of a full length cDNA. Diabetes 41: 807-811

9. Matsutani A, Janssen R, Donis-Keller H, Permutt MA (1992) A polymorphic $(\mathrm{CA})_{\mathrm{n}}$ repeat element maps the human glucokinase GCK (E.C.2.7.1.1) gene to chromosome 7p. Genomics 12:319 325

10. Tanizawa Y, Matsutani A, Chiu KC, Permutt MA (1992) Glucokinase gene: isolation, structural characterization and identification of a microsatellite polymorphism. Molec Endocrinol 6: $1070-1081$

11. Nishi S, Stoffel M, Xiang K, Bell GI, Takeda J (1992) Human pancreatic beta-cell glucokinase gene: cDNA sequence and localization of the polymorphic gene to chromosome 7 , band $\mathrm{p} 13$. Diabetologia 35: 743-747

12. Stoffel M, Froguel Ph, Takeda J et al.(1992) Human glucokinase gene: isolation, characterization, and identification of two missense mutations linked to early-onset non-insulin-dependent (type 2) diabetes mellitus. Proc Natl Acad Sci USA 89: 76987702

13. Froguel $\mathrm{Ph}$, Vaxillaire $\mathrm{M}$, Sun $\mathrm{F}$ et al. (1992) The glucokinase locus on chromosome $7 \mathrm{p}$ is closely linked to early onset non-insulin-dependent diabetes mellitus. Nature 356: 162-164

14. Hattersley AT, Turner RC, Permutt MA et al. (1992) Type 2 diabetes is linked to the glucokinase gene in a large pedigree. Lancet 339: 1307-1310

15. Vionnet N, Stoffel M, Takeda J et al. (1992) Nonsense mutation in the glucokinase gene causes early-onset non-insulin dependent diabetes mellitus. Nature 356: 721-722

16. Stoffel M, Patel P, Lo YMD et al. (1992) Missense mutation in maturity-onset diabetes of the young and mutation screening in late-onset diabetes. Nature Genetics 2: 153-156

17. Froguel Ph, Vionnet N, Stoffel M et al. (1992) Different phenotypic expression by three mutant alleles of glucokinase gene in MODY. Diabetologia 35 [Suppl1]:124 A (Abstract)

18. Velho G, Froguel Ph, Clement K et al. (1992) Primary pancreatic beta-cell secretory defect caused by mutations in glucokinase gene in kindreds of maturity onset diabetes of the young. Lancet 340: 444-448

19. O'Rahilly, S, Wainscoat JS, Turner RC (1988) Type 2 (non-insulin dependent) diabetes mellitus: new genetics for old nightmares. Diabetes 31: 407-414

20. Lander ES, Botstein D (1986) Strategies for studying heterogeneous genetic traits in humans by using a linkage map of restriction fragment length polymorphisms. Proc Natl Acad Sci USA 83: $7353-7357$

21. Cox NJ, Bell GI (1989) Disease associations: chance, artifact, or susceptibility genes? Diabetes 38: 947-950

22. Chiu KC, Province MA, Permutt MA (1992) The glucokinase gene is a genetic marker for non-insulin dependent diabetes mellitus in American Blacks. Diabetes 41: 843-849

23. Chiu KC, Province MA, Dowse GK et al. (1992) A genetic marker at the glucokinase gene locus for non-insulin-dependent diabetes mellitus in Mauritian Creoles. Diabetologia 35:632-638

24. Morgan R, Bishop A, Owens DR, Luzio SD, Peters JR, Rees A (1990) Allelic variants at insulin-receptor and insulin gene loci and susceptibility to NIDDM in Welsh-population. Diabetes 39: 1479-1484

25. Choi W, O'Rahilly S, Buse JB et al. (1991) Molecular scanning of insulin-responsive glucose transporter (Glut4) gene in NIDDM subjects. Diabetes 40:1712-1718

26. Grizzle JE, Starmer CF, Koch GG (1969) Analysis of categorical data by linear models. Biometrics 25: 489-504

27. Orita M, Suzuki Y, Sekiya T, Hayashi K (1989) Rapid and sensitive detection of point mutations and DNA polymorphisms using the polymerase chain reaction. Genomics 5: 874-879

28. Cox NJ, Xiang K-S, Fajans SS, Bell GI (1992) Mapping diabetessusceptibility genes. Lessons learned from search for DNA marker for maturity-onset diabetes of the young. Diabetes 41 : 401-407

29. Bodmer WF (1986) Human genetics: the molecular challenge. In: Cold Spring Harbor symposia on quantitative biology, vol LI: molecular biology of homo sapiens. Cold Spring Harbor Laboratory Press, New York, pp 1-13

30. Cook JTE, Hattersley AT, Christopher P et al. (1992) Linkage analysis of glucokinase gene with NIDDM in caucasian pedigrees. Diabetes 41: 1496-1500

31. Elbein SC, Hoffman M, Chiu KC, Tanizawa Y, Permutt MA (1993) Linkage analysis of the glucokinase locus in familial type 2 (non-insulin-dependent) diabetic pedigrees. Diabetologia 36: $141-145$

Received: 29 September 1992 and in revised form: 8 December 1992

Dr. M. A. Permutt

Metabolism Division

Washington University School of Medicine

660 South Euclid, Box 8127

St. Louis, MO 63110, USA 